\title{
The need for new acutely acting antimigraine drugs: moving safely outside acute medication overuse
}

\author{
Willem Sebastiaan van Hoogstraten ${ }^{1}$ and Antoinette MaassenVanDenBrink ${ }^{2^{*}}$
}

\begin{abstract}
Background: The treatment of migraine is impeded by several difficulties, among which insufficient headache relief, side effects, and risk for developing medication overuse headache $(\mathrm{MOH})$. Thus, new acutely acting antimigraine drugs are currently being developed, among which the small molecule CGRP receptor antagonists, gepants, and the $5-\mathrm{HT}_{1 \mathrm{~F}}$ receptor agonist lasmiditan. Whether treatment with these drugs carries the same risk for developing $\mathrm{MOH}$ is currently unknown.

Main body: Pathophysiological studies on $\mathrm{MOH}$ in animal models have suggested that decreased 5hydroxytryptamine (5-HT, serotonin) levels, increased calcitonin-gene related peptide (CGRP) expression and changes in 5-HT receptor expression (lower $5-\mathrm{HT}_{1 \mathrm{~B} / \mathrm{D}}$ and higher $5-\mathrm{HT}_{2 \mathrm{~A}}$ expression) may be involved in $\mathrm{MOH}$. The decreased $5-\mathrm{HT}$ may increase cortical spreading depression frequency and induce central sensitization in the cerebral cortex and caudal nucleus of the trigeminal tract. Additionally, low concentrations of 5-HT, a feature often observed in $\mathrm{MOH}$ patients, could increase CGRP expression. This provides a possible link between the pathways of 5-HT and CGRP, targets of lasmiditan and gepants, respectively. Since lasmiditan is a $5-\mathrm{HT}_{1 F}$ receptor agonist and gepants are CGRP receptor antagonists, they could have different risks for developing $\mathrm{MOH}$ because of the different (over) compensation mechanisms following prolonged agonist versus antagonist treatment.

Conclusion: The acute treatment of migraine will certainly improve with the advent of two novel classes of drugs, i.e., the $5-\mathrm{HT}_{1 \mathrm{~F}}$ receptor agonists (lasmiditan) and the small molecule CGRP receptor antagonists (gepants). Data on the effects of $5-\mathrm{HT}_{1 \mathrm{~F}}$ receptor agonism in relation to $\mathrm{MOH}$, as well as the effects of chronic CGRP receptor blockade, are awaited with interest.
\end{abstract}

Keywords: Migraine, Medication overuse headache, Chronic migraine, Acute antimigraine drugs, Triptans, Gepants, Ditans, Lasmiditan

\section{Background}

The neurovascular disorder migraine is one of the most common diseases worldwide $[1,2]$. While the group of headache disorders is one of the top three causes of years lost to disease (YLDs), migraine is responsible for approximately $87 \%$ of these YLDs [3]. Migraine treatment can be divided into acutely acting and preventive treatment. The acutely acting treatment can be further subdivided into migraine-specific treatment and analgesics, which are non-specific drugs [4]. Unfortunately, the

\footnotetext{
* Correspondence: a.vanharen-maassenvandenbrink@erasmusmc.nl ${ }^{2}$ Div. of Pharmacology, Dept. of Internal Medicine, Erasmus University Medical Centre, PO Box 2040, 3000, CA, Rotterdam, The Netherlands Full list of author information is available at the end of the article
}

current acutely acting treatments do not provide adequate relief of migraine symptoms for all patients [4-6] and, when used frequently, can cause the disease to develop into medication overuse headache $(\mathrm{MOH})$ [7-9], a debilitating disorder estimated to be responsible for approximately $2 \%$ of all YLDs [10]. $\mathrm{MOH}$ is defined as headache for $\geq 15$ days per month in a patient with pre-existing primary headache, while taking acutely acting medication for 3 months and $\geq 10$ or $\geq 15$ days per month, in case of specific anti-migraine drugs or simple analgesics, respectively $[3,7]$.

This unmet need for adequate and safe treatment of migraine has resulted in the development of new drugs, among which $5-\mathrm{HT}_{1 \mathrm{~F}}$ receptor agonists such as 
lasmiditan, and small molecule CGRP receptor antagonists (gepants) [11-13]. Even though uncertainties regarding long-term effects and precise mechanism of action remain [14-17] and the development of some gepants [18-20] was terminated because of pharmacokinetic or safety concerns, the gepants that are still in development and lasmiditan show promising results in terms of efficacy and side-effects $[4,5,21]$. However, their relationship with medication overuse headache has obviously not yet been described because of the novelty of these drugs. For example, the mean duration until onset of $\mathrm{MOH}$ for triptans, ergots, and analgesics is 1.7 years, 2.7 years, and 4.8 years, respectively [22]. This makes it impossible to draw conclusions based upon clinical trials regarding the long-term use of gepants and lasmiditan, and $\mathrm{MOH}$, not knowing what the duration until onset, if there is any $\mathrm{MOH}$, might be for these new drugs.

From epidemiological, clinical, and fundamental animal studies, a substantial amount of evidence regarding the pathophysiology of $\mathrm{MOH}$ is available [8, 22-26], we will in this review combine this with the current knowledge about the characteristics of CGRP, gepants, and lasmiditan [12, 27-32] in an attempt to generate a relevant hypothesis regarding $\mathrm{MOH}$ and these novel acutely acting antimigraine drugs. To achieve this, we will first shortly review the drugs currently used in the treatment of migraine, after which $\mathrm{MOH}$ and its pathophysiology will be discussed, to conclude with new acutely acting drugs in development, and how these drugs are expected to relate to $\mathrm{MOH}$.

\section{Current acutely acting antimigraine drugs}

The most commonly used approaches for the acute treatment of migraine have been extensively reviewed from several perspectives $[4,13,33-35]$. These approaches include the administration of ergot alkaloids (ergots), triptans, NSAIDs, and paracetamol. NSAIDs and paracetamol are both effective in the treatment of migraine, but are considered to be non-specific antimigraine drugs, as they are general analgesics [36-38]. The oldest migraine-specific drugs are the ergots, dating back to before $1900[39,40]$. Even though several ergots have been shown to be effective against migraine, dihydroergotamine (DHE) is the best tolerated of this class. However, DHE still has more adverse effects than the current drugs. Thus, in practice, $5-\mathrm{HT}_{1 \mathrm{~B} / 1 \mathrm{D}}$ agonists (triptans [41]) are most commonly used. However, a significant proportion of migraine patients experiences insufficient relieve of their attacks, and triptans and ergots are contraindicated in patients with increased cardiovascular risk [42-44]. Additionally, frequent use of any acutely acting antimigraine drugs carries a risk for developing $\mathrm{MOH}$. This results in inadequate treatment of the migraine population as a whole.

\section{Medication overuse headache}

As described above, $\mathrm{MOH}$ is a disorder with headache for $\geq 15$ days per month in a patient with pre-existing headache, while taking acutely acting medication for $\geq 3$ months according to certain requirements [3]. From a clinical perspective, $\mathrm{MOH}$ is present in about $1 \%$ of the general population, and develops mainly in patients with pre-existing migraine (ca. $70 \%$ of all $\mathrm{MOH}$ cases), or tension-type headache $[24,45]$ with chronic migraine (CM) being a form of migraine with especially high prevalence of $\mathrm{MOH}$ [45]. All classes of acutely acting antimigraine drugs are able to cause development of $\mathrm{MOH}[22,23]$, although clinical differences, such as different mean duration until onset of $\mathrm{MOH}$, remain [22]. $\mathrm{MOH}$ patients exhibit, in general, several behavioral characteristics that are also seen in substance abuse or drug addiction [46, 47]. This seems to be in accordance with observations regarding the relapse rate after successful treatment. Although this rate is variable across studies from various countries investigating different separate populations (e.g. populations with triptan overuse, opioid overuse, and / or comorbid psychiatric disorders), the majority shows a relapse rate of $25-35 \%$ [ 45 , 48]. Research on the pathophysiology of $\mathrm{MOH}$ has, until now, developed in mainly two directions. The first being epidemiological and clinical research on $\mathrm{MOH}$ patients, the second pertaining to animal models of $\mathrm{MOH}$. Animal models of $\mathrm{CM}$ and $\mathrm{MOH}$ usually (repeatedly) administer acutely acting antimigraine drugs (e.g. sumatriptan, paracetamol, opioids) to induce $\mathrm{MOH}[9$, $25,49-51]$, or apply nitroglycerin (NO donor) [52-54] or an inflammatory soup on the dura mater $[55,56]$ to induce $\mathrm{CM}$ (with features similar to $\mathrm{MOH}$ ). These models exhibit several phenotypes that relate to $\mathrm{CM}$ as well as $\mathrm{MOH}$, such as mechanical hyperalgesia, photophobia, nociceptive behavior, and facial grooming. However, these models are obviously an imperfect representation of the clinical characteristics. For example, a major critique is that these models cause similar phenotypes, but through a completely different mechanism. Although this may be a strong point, it seems to fit with observations in the clinical situation where diverse classes of drugs may cause similar features of $\mathrm{MOH}$. An obvious difference is that $\mathrm{MOH}$ only develops in patients with pre-existing headaches, while in the $\mathrm{MOH}$ models naive mice are exposed to the $\mathrm{MOH}$-inducing drugs. Similarities with the clinical disorders and shortcomings of the animal models are extensively reviewed elsewhere [57]. Utilizing an animal model for $\mathrm{MOH}$, it was shown in 2010 that triptans can induce central sensitization in rats, which could possibly function as a basis for $\mathrm{MOH}$ [9]. Since then, ample studies have confirmed that chronical application of drugs like paracetamol [51] and opiates [29, 58, 59] have 
similar effects, which could possibly underlie the pathogenesis of $\mathrm{MOH}$. Two common observations in $\mathrm{MOH}$ models are that CGRP expression increases [9, 25, 28, $30]$ and $5-\mathrm{HT}_{1 \mathrm{~B} / \mathrm{D}}$ receptor expression decreases $[60,61]$ upon prolonged exposure to antimigraine drugs in animal models. Clinical research has shown that 5-HT levels are decreased in patients with $\mathrm{MOH}[8,26,62]$. This decrease in 5-HT levels might subsequently upregulate the pronociceptive $5-\mathrm{HT}_{2 \mathrm{~A}}$ expression [63]. Such an upregulation of $5-\mathrm{HT}_{2 \mathrm{~A}}$ expression is also observed in animal models of $\mathrm{MOH}$ [51]. Additionally, reduced 5-HT concentrations in animal models resulted in increased amount of CSDs and hyperexcitability in the cortex and the nucleus caudalis of the trigeminal tract [64-66], mimicking clinical observations in patients with migraine and decreased 5-HT levels. Furthermore, these lower 5-HT levels may also increase CGRP expression $[45,63]$, providing a possible connection between the increased CGRP and decreased 5-HT levels observed in $\mathrm{MOH}$ patients. Blocking CGRP receptors with a monoclonal antibody $(\mathrm{mAb})$ has shown to reduce the risk for cutaneous allodynia, which was used as a proxy for $\mathrm{MOH}$ in an animal model utilizing nitroglycerin as inducer [27]. This is in accordance with the concept that increased CGRP levels may be involved in the pathogenesis of $\mathrm{MOH}$ [67], although it should be kept in mind that other recent studies did not confirm that systemic CGRP levels are increased in medication overuse headache $[68,69]$. In conclusion, decreased 5-HT, increased $5-\mathrm{HT}_{2 \mathrm{~A}}$ receptor level and possibly increased CGRP expression seem to be involved in the pathophysiology of $\mathrm{MOH}$, based upon animal research models.

\section{Prospective acutely acting antimigraine drugs}

The development of new acutely acting drugs has mainly been driven by growing understanding of the pathophysiology of migraine, together with the above-mentioned shortcomings of the currently available drugs. For example, small-molecule CGRP receptor antagonists (gepants) [70], specific 5- $\mathrm{HT}_{1 \mathrm{~F}}$ receptor agonists [21], TRPV1 receptor antagonists [71-73], EP4 receptor (with PGE2 as ligand) antagonists [74], and glutamate receptor antagonists [13] have all been pursued because of their link to migraine pathophysiology [75]. Some of these were, unfortunately, discontinued because of non-superiority over placebo in clinical trials [4]. Currently, the most promising and clinically advanced candidate drugs are lasmiditan $\left(5-\mathrm{HT}_{1 \mathrm{~F}}\right.$ receptor agonist) $[12,21,76,77]$ and gepants (CGRP receptor antagonists) [31, 70, 78, 79]. Lasmiditan is a specific $5-\mathrm{HT}_{1 \mathrm{~F}}$ receptor agonist, whereas triptans have a higher affinity for the $5-\mathrm{HT}_{1 \mathrm{~B} / 1 \mathrm{D}}$ receptors [12]. This difference in affinity is important because triptans are thought to contract the middle meningeal arteries [80], coronary arteries $[43,81]$, and increase the blood pressure [82] through their action on the $5-\mathrm{HT}_{1 \mathrm{~B}}$ receptor [42], for which lasmiditan has no affinity at clinically relevant concentrations. Consequently, where sumatriptan has been shown to have the potential to constrict coronary and carotid arteries in vivo [44] and in vitro [83], lasmiditan did not possess any vasoconstrictor properties in these studies. Because coronary artery constriction brings a cardiovascular risk and lasmiditan does not constrict the coronary arteries either in vitro or in vivo, lasmiditan does not appear to carry the same cardiovascular risk as triptans, which makes it potentially applicable to a wider population. Although it has a lower risk for cardiovascular side effects, lasmiditan may induce central side effects such as dizziness, fatigue, and paresthesia $[12,76]$. Simultaneously with the research focusing on the $5-\mathrm{HT}_{1 \mathrm{~F}}$ receptor agonist lasmiditan, multiple gepants (small molecule CGRP receptor antagonists) are currently being developed for the treatment of migraine [70, 84]. The gepants still in development for the acute treatment of migraine, ubrogepant and rimegepant, show a significant effect compared to placebo, although their efficacy relative to other antimigraine treatments remains to be explored [85]. They seem to cause less side effects than existing anti-migraine drugs, but could potentially carry a cardiovascular risk [16] as CGRP is known to possess cardioprotective properties [86]. Additionally, CGRP/calcitonin knock-out animal models have demonstrated to be more susceptible for hypertension when hypertension is triggered [87, 88]. Presently there is not sufficient evidence to determine whether gepants will have side effects on the cardiovascular system. In summary, the two most promising new acutely acting antimigraine drugs are lasmiditan and the gepants, where lasmiditan has a low cardiovascular risk but central side effects and gepants show the least side effects but potentially could carry a cardiovascular risk, although not sufficient evidence to support or refute this concern is available at the moment.

\section{Pharmacology of lasmiditan, CGRP and MOH}

A question that is of great interest, is whether novel drugs like lasmiditan and the gepants will have the capability to induce $\mathrm{MOH}$. While, as outlined above, the exact mechanisms behind $\mathrm{MOH}$ are currently unknown, it makes sense to hypothesize that $\mathrm{MOH}$ may have to do with desensitization and / or downregulation of the receptors involved in the drug response. It is likely that treatment with agonists will lead to a receptor desensitization and / or downregulation, while treatment with receptor antagonists will lead to receptor upregulation [89] (Fig. 1), as previously reported in depth for the $B$-adrenoceptor agonists used for cardiovascular indications [90]. Besides direct effects on the receptors involved, different classes of drugs leading to $\mathrm{MOH}$ may also affect up- or downregulation of the targeted receptor / pathways, potentially 


\section{A Healthy condition}

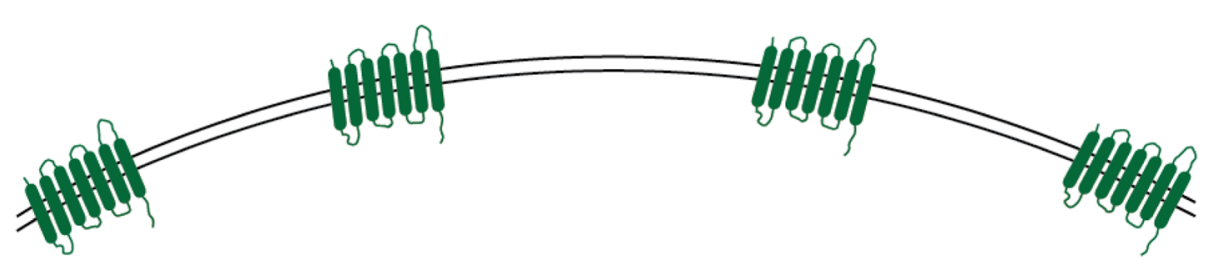

B Agonist treatment
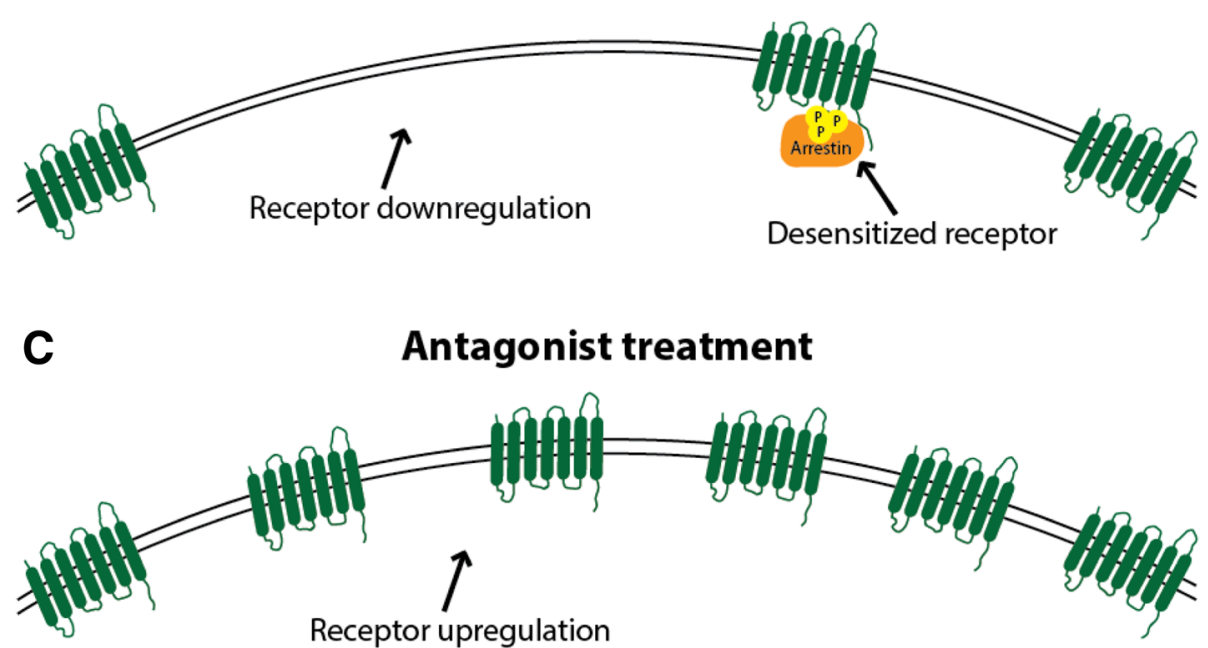

Fig. 1 Schematic representation of potential receptor expression changes upon chronic drug use. Receptor expression in the cell membrane in healthy condition (a), after prolonged agonist exposure (b), and after prolonged antagonist exposure (c). After prolonged agonist exposure, downregulation and desensitization (by arrestin binding after phosphorylation by GPCR Kinase) could occur. After prolonged antagonist exposure, receptor upregulation is expected to take place

leading to a common downstream mechanism inducing $\mathrm{MOH}$. Admittedly, many aspects, such as differential intracellular signaling pathways [91] are still incompletely understood. In addition, migraine patients may have a specific (epi) genetic propensity leading to $\mathrm{MOH}$, which may not be reflected in animal models. While triptans are known to have the propensity of inducing $\mathrm{MOH}$ when taken too frequently, it is not known whether selective $5-\mathrm{HT}_{1 \mathrm{~F}}$ receptor agonists, such as lasmiditan, carry the same risk. Theoretically, this could be possible because the $5-\mathrm{HT}_{1 \mathrm{~B}}, 5-\mathrm{HT}_{1 \mathrm{D}}$ and $5-\mathrm{HT}_{1 \mathrm{~F}}$ receptors all bind to a $\mathrm{G}_{\mathrm{i} / \mathrm{o}}$-coupled receptor and negatively couple to adenylyl cyclase and, thus, share the same effect: decreased production of cyclic AMP $[92,93]$. On the other hand, stimulation of the $5-\mathrm{HT}_{1 \mathrm{~F}}$ (as well as $5-\mathrm{HT}_{1 \mathrm{D}}$ ) receptor, which has been described to be present in blood vessels [94], does not constrict these blood vessels, despite the shared second messenger pathway with the $5-\mathrm{HT}_{1 \mathrm{~B}}$ receptor, underlining that not all characteristics of stimulation of certain receptors can be predicted based on their shared intracellular signaling pathways. Clearly, $5-\mathrm{HT}_{1 \mathrm{~B} / 1 \mathrm{D}}$ receptor agonists with a poor potency at the $5-\mathrm{HT}_{1 \mathrm{~F}}$ receptor, such as ergotamine, are also capable of inducing $\mathrm{MOH}$ [95], so the $5-\mathrm{HT}_{1 \mathrm{~F}}$ receptor is not required for this phenomenon. There are, to the best of our knowledge, currently no data suggesting that the $5-\mathrm{HT}_{1 \mathrm{~F}}$ receptor would or would not be involved in the generation of $\mathrm{MOH}$, so clinical data on the frequent use of $5-\mathrm{HT}_{1 \mathrm{~F}}$ receptor agonists such as lasmiditan are awaited with interest.

Regarding CGRP receptor blockade, chronic and frequent administration of gepants has been attempted in clinical trials investigating prophylactic treatment of migraine [19, 84, 96, 97], and chronic blockade of the CGRP receptor is also achieved by administration of the monoclonal antibody erenumab. Currently, there are no data suggesting that chronic blockade of the CGRP receptor will induce $\mathrm{MOH}$, although long-term effects of administration of CGRP (receptor) - blocking drugs on CGRP receptor signaling should definitely be studied [98]. While blocking CGRP (receptors) is an effective approach for treating migraine, chronic use could in theory result in an increase of CGRP (receptor) expression. However, it is currently unknown whether expression of 
CGRP (receptors) will increase or decrease under these circumstances [98]. Furthermore, the hypothesis that CGRP has an indirect and direct positive feedback loop was proposed by Russo in 2015 [15]. This would, in theory, imply that (chronically) blocking CGRP would not be answered with an (over) compensation or upregulation of CGRP receptors. For 5-HT, on the contrary, applying triptans results in a decrease in 5-HT levels. In summary, it will be fascinating to study the consequences of, and potential differences between, the chronic administration of 5-HT receptor agonists and CGRP receptor antagonists.

\section{CGRP and medication overuse headache}

As described above, CGRP is a central component of migraine. Levels of CGRP are increased in animal models of $\mathrm{MOH}$, which is probably reflecting CGRP levels in $\mathrm{MOH}$ patients [67-69], and blocking CGRP with an antibody prevents the development of a proxy for $\mathrm{MOH}$ in a rodent model [27]. Not only does blocking CGRP (receptors) seem to prevent $\mathrm{MOH}$ formation, but also has it been shown to reduce headache in clinical trials of MOH treatment [99-101]. In summary, 1) currently no conclusion can be drawn as to whether CGRP, or CGRP receptor, expression will increase upon blockade of either of the two; 2) blocking the CGRP pathway prevents formation of a proxy of $\mathrm{MOH}$ in a rodent model [27]; and 3) reduces headache in clinical trials of $\mathrm{MOH}$ treatment [99-101]. Thus, the CGRP pathway seems to be a possible candidate in the safe acute (and preventive) treatment of migraine, maintaining a low risk for $\mathrm{MOH}$ development. Possibly, it could even contribute to symptom alleviation in already clinically established $\mathrm{MOH}$. However, the effects of long-term blockade of CGRP or its receptors remain to be investigated properly.

\section{Other novel acutely acting antimigraine drugs and medication overuse headache}

Opposed to current acutely acting antimigraine drugs and drugs acting on the CGRP pathway, the relationship with $\mathrm{MOH}$ has not extensively been discussed or investigated for novel acutely acting antimigraine drugs. For example, although lasmiditan has been extensively investigated with regard to risk for cardiovascular side effects and efficacy of migraine treatment as described above, currently no data are available regarding its relation to $\mathrm{MOH}$ [102]. To estimate the risk for $\mathrm{MOH}$ development in patients using lasmiditan, several aspects of the drug should be considered, as mentioned above in this review. We look forward to novel studies shedding more light on these characteristics of the prospective antimigraine drugs.

\section{Conclusion}

In conclusion, the acute treatment of migraine will certainly improve with the advent of two novel classes of drugs, i.e., the $5-\mathrm{HT}_{1 \mathrm{~F}}$ receptor agonists and the small molecule CGRP receptor antagonists (gepants). Data on the effects of $5-\mathrm{HT}_{1 \mathrm{~F}}$ receptor agonism in relation to $\mathrm{MOH}$, as well as the effects of chronic CGRP receptor blockade, are awaited with interest.

\section{Abbreviations}

5-HT: 5-hydroxytryptamine, serotonin; CGRP: calcitonin gene related peptide; CM: chronic migraine; CSD: cortical spreading depression;

DHE: dihydroergotamine:; E4: prostaglandin E2 receptor 4; mAb: monoclonal antibody; MOH: medication overuse headache; NO: nitric oxide; NSAIDs: nonsteroidal anti-inflammatory drugs; PGE2: prostaglandin E2; TRPV1: transient receptor potential vannilloid 1; YLDs: years lost to disease

\section{Acknowledgements}

The APCs (article processing charges) for the articles in this thematic series The Changing faces of migraine' were made possible through independent educational sponsorship by Eli Lilly. Eli Lilly provided the funds through an educational grant which included enduring materials within the context of a symposium at the 12th European Headache Federation Congress in September 2018, chaired by Paolo Martelletti. This grant was provided to Springer Healthcare IME who organized the symposium and all of the enduring materials. Three of the articles in this thematic series were developed from content presented at the symposium. Eli Lilly were not involved in the planning of the thematic series, the selection process for topics, nor in any peer review or decision-making processes.

The articles have undergone the journal's standard peer review process overseen by the Editor-in-Chief. For articles where the Editor-in-Chief is an author, the peer review process was overseen by one of the other Editors responsible for this thematic series.

\section{Availability of data and materials}

NA

\section{Authors' contributions}

WSvH and AMvdB both participated in the initial concept of this review, as well as in interpreting the available literature and writing of the manuscript. Both authors read and approved the final manuscript.

\section{Ethics approval and consent to participate} NA

\section{Consent for publication}

NA

\section{Competing interests}

WSvH reports no conflict of interest. AMvdB received research grants, consultation fees and/or travel support from Amgen/Novartis, Eli Lilly/ CoLucid, Teva and ATI.

\section{Publisher's Note}

Springer Nature remains neutral with regard to jurisdictional claims in published maps and institutional affiliations.

\section{Author details}

'Dept. of Neuroscience Erasmus University Medical Centre, PO Box 2040, 3000, CA, Rotterdam, The Netherlands. ${ }^{2}$ Div. of Pharmacology, Dept. of Internal Medicine, Erasmus University Medical Centre, PO Box 2040, 3000, CA, Rotterdam, The Netherlands. 
Received: 26 February 2019 Accepted: 26 April 2019

\section{Published online: 16 May 2019}

\section{References}

1. Bigal ME, Lipton RB (2009) The epidemiology, burden, and comorbidities of migraine. Neurol Clin 27:321-334

2. Steiner TJ, Stovner LJ, Birbeck GL (2013) Migraine: the seventh disabler. Cephalalgia 33:289-290

3. Disease GBD, Injury I, Prevalence, C. Global (2018) Regional, and national incidence, prevalence, and years lived with disability for 354 diseases and injuries for 195 countries and territories, 1990-2017: a systematic analysis for the global burden of Disease study 2017. Lancet 392:1789-1858

4. Monteith TS, Goadsby PJ (2011) Acute migraine therapy: new drugs and new approaches. Curr Treat Options Neurol 13:1-14

5. Wrobel Goldberg S, Silberstein SD (2015) Targeting CGRP: a new era for migraine treatment. CNS Drugs 29:443-452

6. Cady RJ, Shade CL, Cady RK (2012) Advances in drug development for acute migraine. Drugs 72:2187-2205

7. Headache Classification Committee of the International Headache Society (2018) (IHS) the international classification of headache disorders. 3rd edition Cephalalgia 38:1-211

8. Srikiatkhachorn A, Maneesri S, Govitrapong P, Kasantikul V (1998) Derangement of serotonin system in migrainous patients with analgesic abuse headache: clues from platelets. Headache 38:43-49

9. De Felice $M$ et al (2010) Triptan-induced latent sensitization: a possible basis for medication overuse headache. Ann Neurol 67:325-337

10. Steiner $\mathrm{T}$ (2014) Can we know the prevalence of $\mathrm{MOH}$ ? Cephalalgia 34: 403-404

11. Edvinsson L, Villalon CM, MaassenVanDenBrink A (2012) Basic mechanisms of migraine and its acute treatment. Pharmacol Ther 136:319-333

12. Rubio-Beltran E, Labastida-Ramirez A, Villalon CM, MaassenVanDenBrink A (2018) Is selective 5-HT1F receptor agonism an entity apart from that of the triptans in antimigraine therapy? Pharmacol Ther 186:88-97

13. Chan KY, Vermeersch S, de Hoon J, Villalon CM, Maassenvandenbrink A (2011) Potential mechanisms of prospective antimigraine drugs: a focus on vascular (side) effects. Pharmacol Ther 129:332-351

14. Edvinsson $L$ (2015) CGRP receptor antagonists and antibodies against CGRP and its receptor in migraine treatment. Br J Clin Pharmacol 80:193-199

15. Russo AF (2015) CGRP as a neuropeptide in migraine: lessons from mice. $\mathrm{Br}$ J Clin Pharmacol 80:403-414

16. MaassenVanDenBrink A, Meijer J, Villalon CM, Ferrari MD (2016) Wiping out CGRP: potential cardiovascular risks. Trends Pharmacol Sci 37:779-788

17. Arulmani U, Maassenvandenbrink A, Villalon CM, Saxena PR (2004) Calcitonin gene-related peptide and its role in migraine pathophysiology. Eur J Pharmacol 500:315-330

18. Tepper SJ, Cleves C (2009) Telcagepant, a calcitonin gene-related peptide antagonist for the treatment of migraine. Curr Opin Investig Drugs 10:711720

19. Ho TW et al (2011) Antimigraine efficacy of telcagepant based on patient's historical triptan response. Headache 51:64-72

20. Olesen $\mathrm{J}$ et al (2004) Calcitonin gene-related peptide receptor antagonist BIBN 4096 BS for the acute treatment of migraine. N Engl J Med. https://doi. org/10.1056/nejmoa030505

21. Farkkila $\mathrm{M}$ et al (2012) Efficacy and tolerability of lasmiditan, an oral 5-HT (1F) receptor agonist, for the acute treatment of migraine: a phase 2 randomised, placebo-controlled, parallel-group, dose-ranging study. Lancet Neurol 11:405-413

22. Limmroth V, Katsarava Z, Fritsche G, Przywara S, Diener HC (2002) Features of medication overuse headache following overuse of different acute headache drugs. Neurology 59:1011-1014

23. Katsarava Z, Fritsche G, Muessig M, Diener HC, Limmroth V (2001) Clinical features of withdrawal headache following overuse of triptans and other headache drugs. Neurology 57:1694-1698

24. Lance F, Parkes C, Wilkinson M (1988) Does analgesic abuse cause headaches de novo? Headache 28:61-62

25. Yisarakun W et al (2015) Up-regulation of calcitonin gene-related peptide in trigeminal ganglion following chronic exposure to paracetamol in a CSD migraine animal model. Neuropeptides 51:9-16

26. Srikiatkhachorn A, Anthony M (1996) Platelet serotonin in patients with analgesic-induced headache. Cephalalgia 16:423-426
27. Kopruszinski CM et al (2017) Prevention of stress- or nitric oxide donorinduced medication overuse headache by a calcitonin gene-related peptide antibody in rodents. Cephalalgia 37:560-570

28. Belanger S, Ma W, Chabot JG, Quirion R (2002) Expression of calcitonin gene-related peptide, substance $P$ and protein kinase $C$ in cultured dorsal root ganglion neurons following chronic exposure to mu, delta and kappa opiates. Neuroscience 115:441-453

29. Tumati S, Roeske WR, Vanderah TW, Varga EV (2010) Sustained morphine treatment augments prostaglandin E2-evoked calcitonin gene-related peptide release from primary sensory neurons in a PKA-dependent manner. Eur J Pharmacol 648:95-101

30. Yan H, Yu LC (2013) Expression of calcitonin gene-related peptide receptor subunits in cultured neurons following morphine treatment. Neurosci Lett 544:52-55

31. Ho TW, Edvinsson L, Goadsby PJ (2010) CGRP and its receptors provide new insights into migraine pathophysiology. Nat Rev Neurol 6:573-582

32. Villalon CM, Olesen J (2009) The role of CGRP in the pathophysiology of migraine and efficacy of CGRP receptor antagonists as acute antimigraine drugs. Pharmacol Ther 124:309-323

33. Ferrari MD, Roon Kl, Lipton RB, Goadsby PJ (2001) Oral triptans (serotonin 5HT (1B/1D) agonists) in acute migraine treatment: a meta-analysis of 53 trials. Lancet 358:1668-1675

34. Kalra AA, Elliott D (2007) Acute migraine: current treatment and emerging therapies. Ther Clin Risk Manag 3:449-459

35. Gelfand AA, Goadsby PJ (2012) A Neurologist's guide to acute migraine therapy in the emergency room. Neurohospitalist 2:51-59

36. Lipton RB, Baggish JS, Stewart WF, Codispoti JR, Fu M (2000) Efficacy and safety of acetaminophen in the treatment of migraine: results of a randomized, double-blind, placebo-controlled, population-based study. Arch Intern Med 160:3486-3492

37. Silberstein, S. D. Practice parameter: evidence-based guidelines for migraine headache (an evidence-based review): report of the quality standards Subcommittee of the American Academy of neurology. Neurology 55, 754762 (2000)

38. Diener HC (1999) Efficacy and safety of intravenous acetylsalicylic acid lysinate compared to subcutaneous sumatriptan and parenteral placebo in the acute treatment of migraine. A double-blind, double-dummy, randomized, multicenter, parallel group study. The ASASUMAMIG St Cephalalgia 19:581-588; discussion 542

39. Silberstein SD, McCrory DC (2003) Ergotamine and dihydroergotamine: history, pharmacology, and efficacy. Headache 43:144-166

40. Dahlof C, Maassen Van Den Brink AD (2012) Ergotamine, methysergide and sumatriptan - basic science in relation to migraine treatment. Headache 52 : 707-714

41. Saxena PR, Ferrari MD (1989) 5-HT (1)-like receptor agonists and the pathophysiology of migraine. Trends Pharmacol Sci 10:200-204

42. Maassen Van Den Brink A, Saxena PR (2004) Coronary vasoconstrictor potential of triptans: a review of in vitro pharmacologic data. Headache 44(Suppl 1):S13-S19

43. MaassenVanDenBrink A, Reekers M, Bax WA, Ferrari MD, Saxena PR (1998) Coronary side-effect potential of current and prospective antimigraine drugs. Circulation 98:25-30

44. Rubio-Beltrán Haanes K, Labastida A, de Vries R, Danser J, Michael G et al (2016) E. Lasmiditan and sumatriptan: comparison of in vivo vascular constriction in the dog and in vitro contraction of human arteries. Cephalalgia 36:104-105

45. Diener HC, Holle D, Solbach K, Gaul C (2016) Medication-overuse headache: risk factors, pathophysiology and management. Nat Rev Neurol 12:575-583

46. Calabresi P, Cupini LM (2005) Medication-overuse headache: similarities with drug addiction. Trends Pharmacol Sci 26:62-68

47. Kristoffersen ES, Lundqvist C (2014) Medication-overuse headache: a review. J Pain Res 7:367-378

48. Chiang CC, Schwedt TJ, Wang SJ, Dodick DW (2016) Treatment of medication-overuse headache: a systematic review. Cephalalgia 36:371-386

49. Green AL et al (2014) Increased susceptibility to cortical spreading depression in an animal model of medication-overuse headache. Cephalalgia 34:594-604

50. De Felice M, Ossipov MH, Porreca F (2011) Persistent medication-induced neural adaptations, descending facilitation, and medication overuse headache. Curr Opin Neurol 24:193-196 
51. Supornsilpchai W, le Grand SM, Srikiatkhachorn A (2010) Involvement of pro-nociceptive 5-HT2A receptor in the pathogenesis of medication-overuse headache. Headache 50:185-197

52. Pradhan AA et al (2014) Characterization of a novel model of chronic migraine. Pain 155:269-274

53. Tipton AF, Tarash I, McGuire B, Charles A, Pradhan AA (2016) The effects of acute and preventive migraine therapies in a mouse model of chronic migraine. Cephalalgia 36:1048-1056

54. Sufka KJ et al (2016) Clinically relevant behavioral endpoints in a recurrent nitroglycerin migraine model in rats. J Headache Pain 17(40)

55. Zhang $M$ et al (2017) Depression and anxiety behaviour in a rat model of chronic migraine. J Headache Pain 18:27

56. Melo-Carrillo A, Lopez-Avila A (2013) A chronic animal model of migraine, induced by repeated meningeal nociception, characterized by a behavioral and pharmacological approach. Cephalalgia 33:1096-1105

57. Chou TM, Chen SP (2018) Animal models of chronic migraine. Curr Pain Headache Rep 22(44)

58. Ma W, Zheng WH, Kar S, Quirion R (2000) Morphine treatment induced calcitonin gene-related peptide and substance $P$ increases in cultured dorsal root ganglion neurons. Neuroscience 99:529-539

59. Tumati S, Yamamura HI, Vanderah TW, Roeske WR, Varga EV (2009) Sustained morphine treatment augments capsaicin-evoked calcitonin generelated peptide release from primary sensory neurons in a protein kinase Aand Raf-1-dependent manner. J Pharmacol Exp Ther 330:810-817

60. Dobson CF, Tohyama Y, Diksic M, Hamel E (2004) Effects of acute or chronic administration of anti-migraine drugs sumatriptan and zolmitriptan on serotonin synthesis in the rat brain. Cephalalgia 24:2-11

61. Reuter U, Salomone S, Ickenstein GW, Waeber C (2004) Effects of chronic sumatriptan and zolmitriptan treatment on 5-HT receptor expression and function in rats. Cephalalgia 24:398-407

62. Srikiatkhachorn A, Anthony M (1996) Serotonin receptor adaptation in patients with analgesic-induced headache. Cephalalgia 16:419-422

63. Srikiatkhachorn A, le Grand SM, Supornsilpchai W, Storer RJ (2014) Pathophysiology of medication overuse headache--an update. Headache 54: 204-210

64. Supornsilpchai W, Sanguanrangsirikul S, Maneesri S, Srikiatkhachorn A (2006) Serotonin depletion, cortical spreading depression, and trigeminal nociception. Headache 46:34-39

65. Saengjaroentham C, Supornsilpchai W, Ji-Au W, Srikiatkhachorn A, Maneesrile Grand S (2015) Serotonin depletion can enhance the cerebrovascular responses induced by cortical spreading depression via the nitric oxide pathway. Int J Neurosci 125:130-139

66. Ie Grand SM, Supornsilpchai W, Saengjaroentham C, Srikiatkhachorn A (2011) Serotonin depletion leads to cortical hyperexcitability and trigeminal nociceptive facilitation via the nitric oxide pathway. Headache 51:1152-1160

67. Cernuda-Morollón E et al (2013) Interictal increase of CGRP levels in peripheral blood as a biomarker for chronic migraine. Neurology. https:// doi.org/10.1212/WNL.0b013e3182a6cb72

68. Lee MJ, Lee SY, Cho S, Kang ES, Chung CS (2018) Feasibility of serum CGRP measurement as a biomarker of chronic migraine: a critical reappraisal. J Headache Pain. https://doi.org/10.1186/s10194-018-0883-x

69. Munksgaard SB et al (2019) Circulating nociceptin and CGRP in medicationoveruse headache. Acta Neurol Scand. https://doi.org/10.1111/ane.13053

70. Messina R, Goadsby PJ (2018) CGRP - a target for acute therapy in migraine: clinical data. Cephalalgia. https://doi.org/10.1177/0333102418768095

71. Quartu M et al (2016) TRPV1 receptor in the human trigeminal ganglion and spinal nucleus: immunohistochemical localization and comparison with the neuropeptides CGRP and SP. J Anat 229:755-767

72. Dussor $\mathrm{G}$ et al (2014) Targeting TRP channels for novel migraine therapeutics. ACS Chem Neurosci 5:1085-1096

73. Meents JE et al (2015) Two TRPV1 receptor antagonists are effective in two different experimental models of migraine. J Headache Pain 16(57)

74. Maubach KA et al (2009) BGC20-1531, a novel, potent and selective prostanoid EP receptor antagonist: a putative new treatment for migraine headache. Br J Pharmacol 156:316-327

75. Stovner LJ, Tronvik E, Hagen K (2009) New drugs for migraine. J Headache Pain 10:395-406

76. Ferrari MD et al (2010) Acute treatment of migraine with the selective 5HT1F receptor agonist lasmiditan--a randomised proof-of-concept trial. Cephalalgia 30:1170-1178
77. Neeb L, Meents J, Reuter U (2010) 5-HT (1F) receptor agonists: a new treatment option for migraine attacks? Neurotherapeutics 7:176-182

78. Deen $\mathrm{M}$ et al (2017) Blocking CGRP in migraine patients - a review of pros and cons. J Headache Pain 18:96

79. Durham PL, Vause CV (2010) Calcitonin gene-related peptide (CGRP) receptor antagonists in the treatment of migraine. CNS Drugs 24:539-548

80. MaassenVanDenBrink A et al (2000) Craniovascular selectivity of eletriptan and sumatriptan in human isolated blood vessels. Neurology 55:1524-1530

81. Maclntyre PD, Bhargava B, Hogg KJ, Gemmill JD, Hillis WS (1993) Effect of subcutaneous sumatriptan, a selective $5 \mathrm{HT} 1$ agonist, on the systemic, pulmonary, and coronary circulation. Circulation 87:401-405

82. de Hoon JN, Willigers JM, Troost J, Struijker-Boudier HA, Van Bortel LM (2000) Vascular effects of 5-HT1B/1D-receptor agonists in patients with migraine headaches. Clin Pharmacol Ther 68:418-426

83. Rubio-Beltrán Labastida-Ramírez A., van den Bogaerdt A., Bogers A. J. J. C., Zanelli E. E. \& Meeus $L$, et al.. In vitro characterization of agonist binding and functional activity at a panel of serotonin receptor subtypes for lasmiditan, triptans and other 5-HT receptor ligands and activity relationships for contraction of human isolated coronary artery. Cephalalgia 37,363 (2017)

84. Schuster NM, Rapoport AM (2017) Calcitonin gene-related peptide-targeted therapies for migraine and cluster headache: a review. Clin Neuropharmacol 40:169-174

85. Tfelt-Hansen P, Loder E (2019) The Emperor's new Gepants: are the effects of the new Oral CGRP antagonists clinically meaningful? Headache. https:// doi.org/10.1111/head.13444

86. Kee Z, Kodji X, Brain SD (2018) The role of calcitonin gene related peptide (CGRP) in neurogenic vasodilation and its Cardioprotective effects. Front Physiol 9(1249)

87. Gangula PR et al (2000) Increased blood pressure in alpha-calcitonin generelated peptide/calcitonin gene knockout mice. Hypertension 35:470-475

88. Smillie SJ et al (2014) An ongoing role of alpha-calcitonin gene-related peptide as part of a protective network against hypertension, vascular hypertrophy, and oxidative stress. Hypertension 63:1056-1062

89. Bohm, S. K., Grady, E. F. \& Bunnett, N. W. Regulatory mechanisms that modulate signalling by G-protein-coupled receptors. Biochem J 322 ( Pt 1, 1-18 (1997)

90. Charlton SJ (2009) Agonist efficacy and receptor desensitization: from partial truths to a fuller picture. Br J Pharmacol 158:165-168

91. Kenakin T (2013) New concepts in pharmacological efficacy at 7TM receptors: IUPHAR review 2. Br J Pharmacol 168:554-575

92. Masson J, Emerit MB, Hamon M, Darmon M (2012) Serotonergic signaling: multiple effectors and pleiotropic effects. Wiley Interdiscip Rev Membr Transp Signal 1:685-713

93. Raymond JR et al (2001) Multiplicity of mechanisms of serotonin receptor signal transduction. Pharmacol Ther 92:179-212

94. Nilsson T et al (1999) Characterisation of 5-HT receptors in human coronary arteries by molecular and pharmacological techniques. Eur J Pharmacol 372:49-56

95. Grazzi L, Grignani E, D'Amico D, Sansone E, Raggi A (2018) Is medication overuse drug specific or not? Data from a review of published literature and from an original study on Italian MOH patients. Curr Pain Headache Rep 22(71)

96. Ho TW et al (2008) Efficacy and tolerability of MK-0974 (telcagepant), a new oral antagonist of calcitonin gene-related peptide receptor, compared with zolmitriptan for acute migraine: a randomised, placebo-controlled, paralleltreatment trial. Lancet 372:2115-2123

97. Ho TW et al (2014) Randomized controlled trial of the CGRP receptor antagonist telcagepant for migraine prevention. Neurology 83:958-966

98. Gingell JJ, Hendrikse ER, Hay DL (2019) New insights into the regulation of CGRP-family receptors. Trends Pharmacol Sci 40:71-83

99. Detke HC et al (2018) Galcanezumab in chronic migraine: the randomized, double-blind, placebo-controlled REGAIN study. Neurology 91:e2211-e2221

100. VanderPluym J et al (2018) Fremanezumab for preventive treatment of migraine: functional status on headache-free days. Neurology 91:e1152-e1165

101. Tepper $S$ et al (2017) Safety and efficacy of erenumab for preventive treatment of chronic migraine: a randomised, double-blind, placebocontrolled phase 2 trial. Lancet Neurol 16:425-434

102. Negro A, Koverech A, Martelletti P (2018) Serotonin receptor agonists in the acute treatment of migraine: a review on their therapeutic potential. J Pain Res 11:515-526 